\title{
Optimizing the facility location design of organ transplant centers
}

\author{
Jeroen Beliën $^{\mathrm{a}, \mathrm{b}, *}$, Liesje De Boeck ${ }^{\mathrm{a}, \mathrm{b}}$, Jan Colpaert ${ }^{\mathrm{a}, \mathrm{b}}$, Stijn Devesse ${ }^{\mathrm{c}}$, Filip Van den Bossche ${ }^{\mathrm{a}, \mathrm{d}}$ \\ a HUBrussel, Center for Modeling and Simulation, Warmoesberg 26, 1000 Brussels, Belgium \\ ${ }^{\mathrm{b}}$ Research Center for Operations Management, Naamsestraat 69, 3000 Leuven, Belgium \\ ${ }^{c} K P M G$, Bourgetlaan 40, 1130 Brussels, Belgium \\ ${ }^{\mathrm{d}}$ Research Center for Operations Research and Business Statistics, Naamsestraat 69, 3000 Leuven, Belgium
}

\section{A R T I C L E I N F O}

Available online $\mathrm{xxxx}$

\section{Keywords:}

Facility location

Organ transplant

Long-term planning

Mixed integer linear programming

\begin{abstract}
A B S T R A C T
This paper presents a mixed integer linear programming (MILP) long-term decision model to optimize the location of organ transplant centers. The objective is to minimize the sum of the weighted time components between the moment a donor organ becomes available and its transplantation into the recipient's body. The weight factor for the elapsed time before the organ's removal from the donor body allows to assign a lower weight to this time component in the objective function in order to reflect the criticality of the process after the organ's removal. The specificity of organ transplants makes the model more complex than a traditional facility location model. The model is applied to the Belgian organ transplant path. Extensive numerical experiments reveal the key factors that impact the long-term decision of centralizing versus decentralizing transplant centers.
\end{abstract}

(C) 2012 Elsevier B.V. All rights reserved.

\section{Introduction}

Transplantation has become a successful treatment for many diseases that otherwise would have been fatal. Advanced surgical techniques and the advent of improved medications, including anti-rejection treatments, have ensured that more people benefit from this major surgery. Organ transplantation involves a donor (a person who donates an organ intended for transplant) and a recipient (a person who receives an organ). Unfortunately, as the demand for organs continues to exceed the supply, organ transplants suffer from long waiting lists. The number of organ transplants in 2009, and the active waiting list in Belgium on December 31, 2009 are represented in Table 1 [11]. Table 1, as well as the remainder of the paper, focuses only on the vital organs (kidney, liver, lung, heart, and pancreas).

Waiting lists are to be found worldwide (see, e.g., [17]). Consequently, many patients are confronted with long waiting times. In addition, the time that elapses between donor notification and transplantation is very important in the process of organ donation. The model presented in this paper will minimize the sum of the weighted time components related to the total transplantation process. However, the longer an organ is outside the donor's body, the lower the quality of the donor organ [36]. Our model takes into account the criticality of the time after the organ

* Corresponding author at: HUBrussel, Center for Modeling and Simulation, Warmoesber 26, 1000 Brussels, Belgium. Tel.: +32 260982 71; fax: + 3222176464 .

E-mail addresses: jeroen.belien@hubrussel.be (J. Beliën),

liesje.deboeck@hubrussel.be (L. De Boeck), jan.colpaert@hubrussel.be (J. Colpaert),

stijn_devesse@hotmail.com (S. Devesse), filip.vandenbossche@hubrussel.be (F. Van den Bossche). removal in two ways. First, the maximum allowed travel times after the removal are constrained by certain limits, further referred to as cold ischemia times. Second, our objective function allows to mainly focus on the time after the organ removal by assigning a lower weight to the elapsed time before the organ's removal from the donor. Fig. 1 shows the total transplantation path for organ transplants in Belgium, indicating all the different travel time components. Note that these travel times are determined by the location of the transplant centers.

The following three situations may occur: (i) a domestic donor supplying a domestic recipient, (ii) a domestic donor supplying a foreign recipient, and (iii) a foreign donor supplying a domestic recipient. We now briefly describe these situations for a good understanding of the remainder of the paper.

In case of a domestic donor (i), the transplantation process starts when this donor 'arrives' in a hospital, referred to as the donor hospital. In a first phase, the transplant co-ordinator (the person who co-ordinates the entire transplantation process) organizes the collection of the donor's blood samples at the donor hospital. These samples are brought to the laboratory of the donor transplant center, further referred to as donor center (a). The blood results are input for a database and an algorithm selecting the recipient. When the transplant co-ordinator agrees, the recipient and recipient transplant center, further referred to as recipient center, are called. The recipient sets out to the recipient center (b). At the same time, the transplant co-ordinator and his/her transplant team travel to the donor hospital (c). The organ is removed from the donor's body and transported to the recipient's center (d) where the transplantation is performed. In the event of a foreign recipient (ii), the organ is transported from the donor hospital to the airport (e). When the donor organ comes from abroad (iii), the organ is transported from the airport to the recipient center (f). 
Table 1

The number of organ transplants in 2009, and the active waiting list on December 31, 2009 (Belgium).

\begin{tabular}{lll}
\hline Organ & Transplants & Active waiting list \\
\hline Kidney & 428 & 866 \\
Liver & 220 & 191 \\
Lung & 90 & 95 \\
Heart & 68 & 58 \\
Pancreas & 42 & 46 \\
\hline
\end{tabular}

We make a distinction between these three situations as they all have a different path and as such, a different travel time.

This paper presents a model to minimize the travel time between donor notification and the organ arrival at the recipient center, taking into account all components of Fig. 1. The model decides which transplant centers to open for which organs (given the location of potential transplant centers). The transplant center locations have a major impact on the travel time from donor hospital to the recipient transplant center. As such, they also influence the time that elapses between removal of the organ from the donor's body and transplantation.

The model belongs to the class of facility location models. It is well-known that facility location decisions support long-term decision making, having a significant impact on performance in terms of costs and responsiveness [7]. The costs correspond to the transplant center installation and operating costs. Responsiveness is related to the different time components in the elapsed time between donor notification and the organ arrival at the recipient center as well as the travel times of the parties involved (transplant coordinator, transplant team, recipient). Note that, in general, decision support related to facility location (see e.g. [19]), the health care sector (see e.g. [13,22]), and facility location in the health care sector [21] is not at all new. However, due to several specificities in organ transplants, our model is more complex than a classical facility location model (see, e.g., [8]). Below, we briefly introduce these specificities.

The model should cover supply (from the donors in a donor hospital), as well as demand (from the recipients in a recipient center). The demand requires a recipient center, while the supply asks for a donor center. All selected transplant centers act both as a donor and recipient center. An open transplant center will always act as donor center for all donor hospitals for which the center is the nearest open center (which follows from the model in Section 4). At the same time, the open center serves a recipient demand and, hence, acts as a recipient center.

Optimizing the transplant center locations requires calculating the resulting organ flows from sources (donor hospitals) to destinations (recipient transplant centers). To quantify these flows we start from the number of transplantations per time period (we will assume this time period to be a year) in each transplant center as well as the supply of organs in the donor hospitals. The number of transplantations executed per time period is what we define as the demand for organs in a potential transplant center. The aggregate demand (the yearly demand of organs in the potential transplant centers for domestic recipients) must equal the aggregate supply (the yearly supply of organs in donor hospitals from domestic and foreign donors). As a consequence, if the model decides a particular transplant center is not open, its demand needs to be processed by another, open recipient center. We assume that the demand of a closed center will shift to the nearest open transplant center. This long-term decision (of which transplant centers to open for which organs) requires a good estimation of the yearly supply of organs in each donor hospital. As this yearly supply appears to be stable throughout the years in Belgium, our model can be directly applied to the Belgian case. For other countries, it might be necessary to incorporate robustness into the model ensuring that the solution performs well over all years. The latter will be discussed in points for future research (Section 6). Note that the dynamics and timing of the real supply and demand processes are irrelevant for this long-term decision model. Also patient prioritization (the patient's ranking in being offered an organ) and patient decision (the patient's final say in terms of whether or not accepting a donor organ) are not considered. Only the supply of the donor hospitals (and the total demand of the potential transplant centers) are relevant in this research as these represent the 'load' the chosen transplant centers will have to process, and, hence, determine the total travel time.

The organ transplant process is constrained by the cold ischemia time. The cold ischemia time is defined as the maximal time the organ can be kept outside the body. The literature (see, e.g., [31] and references therein) reports on a direct negative influence of the duration the organ is outside the donor's body on the chances of a successful transplantation. Banner et al. [4] report on a decrease in the recipient survival rates within 30 days of heart transplantation in the case of longer ischemia times (including transport times and surgical implant times). Hence, organ transport distances are critical to outcome in liver transplantation. If the transport time between a donor hospital and a recipient center exceeds this cold ischemia time for a particular organ, we assume that the organ cannot be transported to the recipient center. Instead, the organ as well as the selected recipient will need to travel to a recipient center situated within a sufficiently small travel time from the donor hospital.

The remainder of the paper is organized as follows. Section 2 represents a literature review on facility location models in general and facility location related to organ transplants. Section 3 describes in more detail the specificities of the organ transplant process in building a transplant center location model. Section 4 presents the MILP model. Section 5 describes the application of the model to the Belgian case, including an extensive sensitivity analysis. Section 6 concludes with the most important findings and presents some interesting directions for future research.

\section{Literature review}

Most work related to organ donations and organ transplants focuses on policies to allocate organs to recipients (see [6,24], and references therein). Within this domain, kidney and liver transplants are most frequently studied, since they constitute the vast majority of transplanted organs (Belgium is no exception, as can be observed from Table 1). For a recent overview of organ allocation and the acceptance of kidneys and livers, we refer to Alagoz et al. [1]. Nevertheless, when looking at the broader health care literature, we observe that facility location is not at all a new issue [24]. This is not surprising, since location of health care delivery has much in common with the location of many other types of facilities: a geographically dispersed customer base, ease or speed of access and the low cost of siting and operations [23].

Daskin and Dean [8] provide a review of discrete facility location models. The models can be regarded as the basis of almost all facility location models used in health care: the set covering, the maximal covering, the P-center, the P-median and the uncapacitated fixed charge location (UFL) models. Four of these models provide full coverage of demand by facilities. They mainly differ in their objective

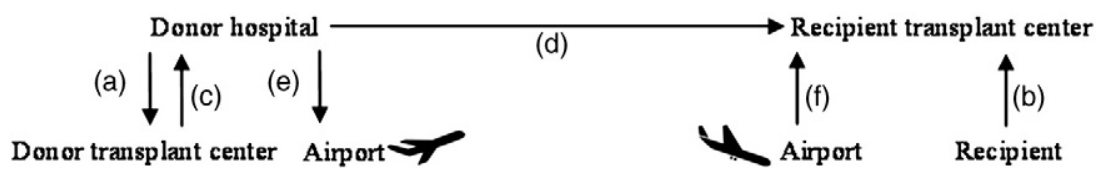

Fig. 1. The time components of the organ transplant path. 
function: minimizing facility costs or facilities (set covering models), minimizing coverage distance (P-center models), minimizing demand weighted total (or average) distance (P-median models), and minimizing facility costs and demand weighted total (or average) distance cost (UFL models). The fifth model maximizes the covered demand (maximal covering models). A bibliography of recent papers related to these models can be found in ReVelle et al. [27].

Our model minimizes the time between donor notification and organ arrival at the recipient center while covering aggregate demand (organs for recipients) and aggregate supply (organs from donors). The time components in the objective function will be weighted by the flow related to each component. Therefore, our model is mostly related to the P-median model (see, e.g., $[10,15,20,27])$. However, the specificities of organ transplants justify a more complex model.

Bruni et al. [6] and Kong et al. [18] are, as far as we know, the only papers in location theory related to organ transplants. Bruni et al. [6] present a mixed integer linear programming (MILP) model that selects the optimal location of recipient centers, donor centers and organ procurement organizations (OPOs). Each OPO is responsible for procuring transplantable organs in a designated service area. Their model has been applied to the Italian transplant system involving three organs: liver, heart and kidney. Kong et al. [18] study the problem of maximizing the efficiency of intraregional transplants in the United States through the redesign of liver allocation regions. They formulate the problem as a set partitioning problem that clusters OPOs into regions. Because the number of potential regions is too large to handle explicitly, a branch-and-price approach is used in which regions are added adaptively through column generation. The difference between these papers and our work is twofold. First, instead of assigning regions to OPOs, we consider the problem within one OPO and decide on the optimal location of transplant centers. Second, our model incorporates five organs (heart, lung, pancreas, kidney and liver) which are linked to each other through an overall budget constraint. As such, our model tries to minimize the required travel times given a limited budget to open transplant centers.

The contribution of this paper is twofold. First, we present a new MILP model aiding in the long-term decision for designing transplant center locations within an OPO. We explain in detail how this model distinguishes from classical facility location problems in Sections 3 and 4. Second, we apply the model to the transplant system in Belgium in order to evaluate a number of scenarios. By comparing the outcomes using real-life data from 2004-2009, we examine the sensitivity of the optimal design with respect to real-life changes in the supply of the donor hospitals and the demand of the potential transplant centers.

\section{Specificities of the organ transplant process}

While traditional location models only cover demand, our model must cover both supply and demand. There is a supply of donor organs in the donor hospitals and a demand of organs of the recipients in the recipient centers. The supply in a donor hospital, for both domestic and foreign recipients, requires a donor center that provides the blood results as well as a transplantation team. The demand of domestic recipients asks for a recipient center performing the organ implantation. As already stated in Section 1, the aggregate demand equals the aggregate supply. The aggregate demand for Belgium in 2009 is presented in Table 1. Because the transplant centers were not eager to disclose their supply data, we had to estimate the annual supply of donor organs in each donor hospital. In Fig. 2, we introduce a simplified representation in order to show how the supply in each donor hospital is estimated when the aggregate demand is known.

In Fig. 2, we assume a country consisting of three donor hospitals and two transplant centers. The number of yearly heart transplants in each recipient center is known (40 for recipient center 1 and 60 for center 2). The supply for each donor hospital is then obtained by multiplying the yearly aggregate demand $(=60+40)$ by the share of the donor hospital's beds in the total number of beds in all donor hospitals $(=120+60+20)$. This reasoning follows from the fact that the number of beds in a donor hospital is a measure of the population the donor hospital covers. Consequently, the number of beds is also a measure for the potential number of donors that a donor hospital will register.

When the yearly supply in each donor hospital and the yearly demand in each recipient center are known, the flow between each donor hospital and each recipient center is fixed. This is shown in Fig. 3.

The demand in each recipient center can be fulfilled by a donor organ from each donor hospital. The flow between a donor hospital and a recipient center is then calculated as the supply in the donor hospital multiplied by the share of organ transplants in a recipient center $(=40 /(40+60)$ for recipient center $1,=60 /(40+60)$ for recipient center 2$)$.

Aggregate supply equal to aggregate demand also means that if the model decides a particular transplant center does not open, the demand will have to shift to another center. We assume that this shift will happen to the nearest open center. This is illustrated in Fig. 4.

Fig. 4 shows how a closure of recipient center 2 causes its demand to shift to the nearest open recipient center (which is recipient center 1 ). The shares of recipient centers 1 and 2 in the total demand become $100 \%$ and $0 \%$, respectively. Consequently, the flow between donor hospitals and recipient centers changes.

If the transport time between a donor hospital and a recipient center exceeds the cold ischemia time for a particular organ, we exclude a flow between both locations for that organ. The organ flow will then be diverted to the nearest open recipient center as represented in Fig. 5.

In Fig. 5, we assume that the travel time between donor hospital 1 and recipient center 2 exceeds the cold ischemia time. As a consequence, the corresponding flow (36) is forbidden. This generates an extra flow (36) to the donor hospital's nearest recipient center (which is center 1 ).

The timely arrival of the recipient also exerts an influence on the cold ischemia time. A longer travel time for the recipient to the recipient center increases the probability of exceeding the cold ischemia time. The model will take this into account by a covering constraint that requires opening at least one transplant center within a maximum driving time from each municipality in a country. We refer to, e.g., Toregas and ReVelle [29], Rajagopalona et al. [25], and Fallah et al. [12], for more information on covering constraints in general. Note that this covering constraint can be seen as a guaranteed service level offered to the recipient.

The above mentioned specificities indicate that once the model has decided on which centers to open for which organs, the related flows between donor hospitals and transplant centers are known. In other words, the flows are immediately derived from the location
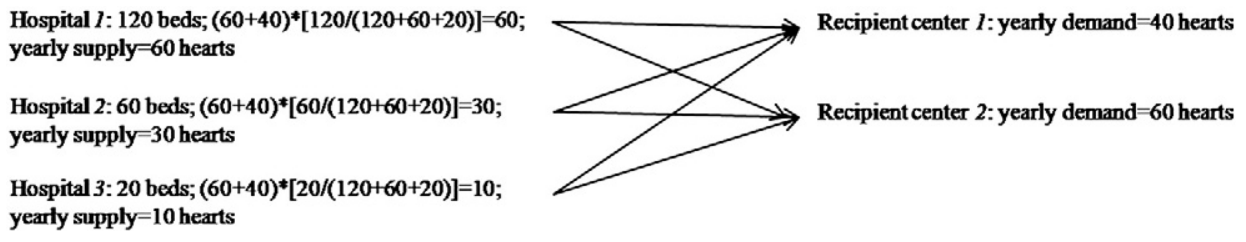

Fig. 2. The yearly heart supply in three donor hospitals given the yearly heart demand in two recipient centers. 


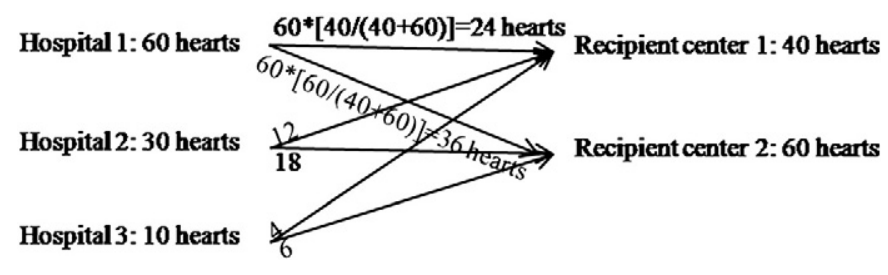

Fig. 3. The flows between donor hospitals and recipient centers.

decisions. Thus, our model is a pure facility location problem and does not decide on the flows between different locations (as is the case in transportation problems).

\section{MILP model}

In this section, we develop the MILP model.

First, we present the symbols we will use. We begin by listing the sets, along with the indices associated with each set.

$$
\begin{aligned}
& c, c^{\prime}, r, r^{\prime} \in C: \text { transplant centers } \\
& o \in O: \text { organs to be transplanted } \\
& h, h^{\prime} \in H: \text { donor hospitals } \\
& m \in M: \text { municipalities } \\
& a \in A: \text { airports }
\end{aligned}
$$

Next, we state the decision variables, coefficients and right hand side constants. We use the following conventions:

- decision variables and coefficients are indicated with a small letter, while right hand side constants are indicated with a capital letter,

- each symbol (decision variable, coefficient or right hand side constant) is denoted by one letter, having at most one superscript and at most three subscripts,

- indices are always written in subscript,

- a superscript is used to distinguish the variable from other similar variables, for example $x_{o h c}^{R}$ denotes the flow to donor (D) centers, while $x_{\text {ohc }}^{R}$ denotes the flow to recipient (R) centers.

We use Fig. 6 to illustrate the flow decision variables. Note that there is no decision variable associated neither with the flow from donor hospitals to airports nor with the flow between recipients and recipient centers. Recall that organs with a destination abroad go directly from the donor hospital to the airport. Thus, the flows between donor hospitals and airports are not influenced by our decision whether or not to open certain transplant centers. Hence, these flows are constants in our problem. The flows between recipients and recipient centers occur in parallel with the other flows. The recipient just needs to be present at the recipient center before the organ arrives. To ensure this, a covering constraint is added to our model that guarantees that each possible recipient (inhabitant) lives within a certain travel time from an open transplant center, and this with respect to each organ (see also points for future research at the end of Section 6).

The decision variables are:

$y_{o c} \in\{0,1\}:=1$ if center $c$ is open for organ $o$ and 0 otherwise $z_{c} \in\{0,1\}:=1$ if center $c$ is open, i.e., open for at least one organ $o$ $x_{\text {ohc }}^{D}$ : flow of organ $o$ from donor hospital $h$ to donor center $c$

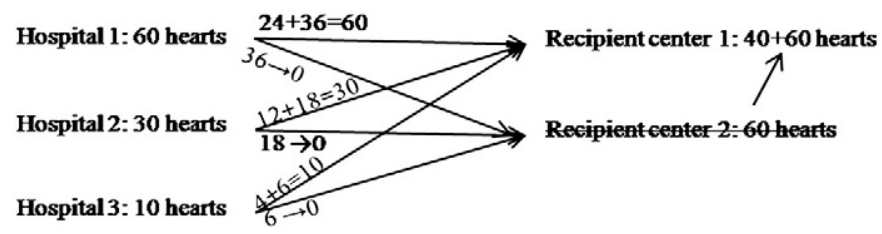

Fig. 4. The flows in case of a demand shift to the nearest open recipient center.

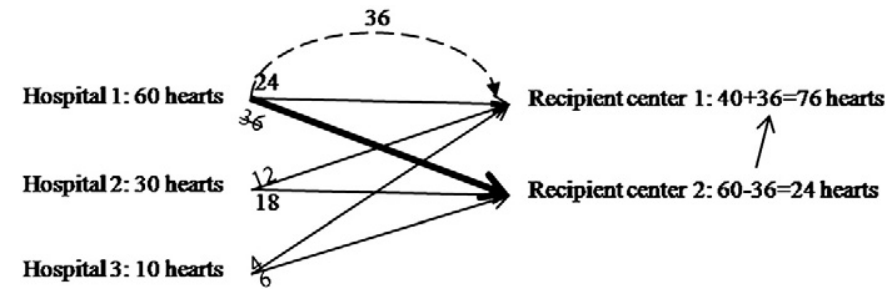

Fig. 5. The flows in case of a demand shift to the nearest open recipient center caused by exceeding the cold schemia time.

$x_{\text {ohc }}^{R}$ : flow of organ $o$ from donor hospital $h$ to recipient center $c$

$x_{o h c}^{E}$ : extra flow of organ $o$ from donor hospital $h$ to recipient center $c$

$x_{o a c}^{A}$ : flow of organ $o$ from airport $a$ to recipient center $c$

$d_{o c}^{A}$ : total (including shifted demand of closed centers) recipient demand for transplantations of organ $o$ at recipient center $c$ coming from foreign donors

$d_{o c^{\prime} c}^{D}$ : recipient demand for transplantations of organ $o$ coming from domestic donors shifted from recipient center $c^{\prime}$ to $c$

$d_{o c^{\prime} c}^{A}$ : recipient demand for transplantations of organ $o$ coming from abroad shifted from recipient center $c^{\prime}$ to $c$.

The decision whether or not to open a transplant center for a particular organ, $y_{o c}$, is the basic decision variable in our problem. All the other decision variables are auxiliary variables, whose values can easily be calculated for a given combination of $y_{o c}$ the flow between donor hospitals, and donor centers, $x_{o h}^{D}$, is minimized by sending each organ that becomes available in a particular donor hospital to the nearest open donor center.

The coefficients and right hand side constants in our MILP model are:

$w$ : weight $(0 \leq w \leq 1)$ that indicates the relative importance in the objective function of the flows during which the organ is still in the donor's body, i.e., the flows between donor hospitals and donor centers, compared to the flows that are subject to the cold ischemia time, i.e., the flows from donor hospitals and airports to recipient centers $D_{o c}^{D}$ : recipient demand for transplantations of organ $o$ at recipient center $c$ coming from domestic donors

$D_{o c}^{A}$ : recipient demand for transplantations of organ $o$ at recipient center $c$ coming from foreign donors

$S_{o h}^{D}$ : donor supply of organ $o$ at donor hospital $h$ for domestic recipients

$S_{o h}^{A}$ : donor supply of organ $o$ at donor hospital $h$ for foreign recipients

$k$ : fixed (overhead) costs for opening a transplant center

$k_{o}$ : cost of opening a center capable of transplanting organ $o$

$B$ : available budget

$I_{o}$ : cold ischemia time for organ $o$

$p_{r c}: r^{\text {th }}$ nearest center to center $c, r \in\{1,2, \ldots,|C|-1\}$

$T_{o}$ : maximal allowed travel time between any municipality and an open center for organ $o$

$t_{m c}^{M}$ : travel time from municipality $m$ to center $c$

$t_{h c}^{T}, t_{c h}^{B}$ : travel time from donor hospital $h$ to donor center $c\left(t_{h c}^{T}\right)$ and back from donor center $c$ to donor hospital $h\left(t_{c h}^{B}\right)$

$t_{a c}^{A}$ : travel time from airport $\alpha$ to recipient center $c$.

Given the organ demand in each recipient center, the foreign demand leaving through airports, the organ supply in each donor hospital, the international organ supply entering through the airports, and the travel times between donor hospitals, airports, municipalities on the one hand and transplant centers on the other hand, our model 

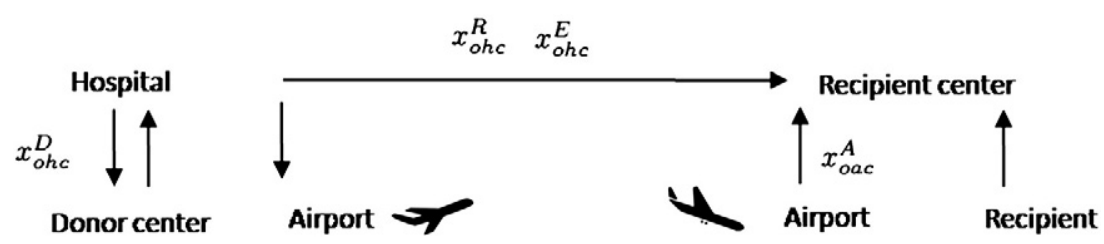

Fig. 6. The flow decision variables.

will select the optimal combination of centers to be open for each organ. This optimal combination minimizes the total travel time, i.e., the total flow of transported organs, each flow multiplied by its required travel time. On the one hand, opening a certain transplant center might be beneficial, because it can act as a donor center for donor hospitals nearby. In particular, an open center leads to a decrease in travel time between donor hospital and donor center for all donor hospitals for which the center is the nearest center. A second reason to open a certain transplant center is to ensure that every inhabitant lives within a maximal travel time from an open center, and this with respect to each organ (covering restriction). On the other hand, opening a transplant center automatically includes that the center will also function as a recipient center, having a certain organ demand. Hence, the drawback of opening a center is that organs will need to be transported from each donor hospital to each open center (provided that the travel time does not exceed the cold ischemia time). A second reason for not opening a transplant center is the budget restriction. Note that in general, opening more centers leads to increased costs and increased responsiveness whereas less centers lead to decreased costs and decreased responsiveness. How this responsiveness translates in both cases, will be discussed in subsection 5.3.

The MILP model can be stated as follows:

$$
\begin{aligned}
& \text { Minimize } \sum_{o \in O} \sum_{h \in H} \sum_{c \in C}\left(w\left(t_{h c}^{T} x_{o h c}^{D}+t_{c h}^{B} x_{o h c}^{D}\right)+t_{h c}^{T} x_{o h c}^{R}\right) \\
& +\sum_{o \in O} \sum_{a \in A} \sum_{c \in C} t_{a c}^{A} x_{o a c}^{A}
\end{aligned}
$$

S.T.

$y_{o c} \leq z_{c} \quad \forall o \in O, c \in C$

$\sum_{c \in C}\left(k z_{c}+\sum_{o \in O} k_{o} y_{o c}\right) \leq B$

$\sum_{h \in H} \sum_{c \in C} x_{o h c}^{R}=\sum_{c \in C} D_{o c}^{D} \forall o \in O$

$x_{\text {ohc }}^{R}=0 \forall 0 \in O, h \in H, c \in C \mid t_{h c}^{T}>I_{o}$

$x_{o h c}^{R}=\left(\frac{D_{o c}^{D} y_{o c}+\sum_{c^{\prime} \in C} d_{o c^{\prime} c}^{D}}{\sum_{c^{\prime} \in C} D_{o c^{\prime}}^{D}}\right) S_{o h}^{D}+x_{o h c}^{E} \quad \forall o \in O, h \in H, c \in C \mid t_{h c}^{T} \leq I_{o}$

$d_{o c^{\prime} c}^{D} \geq\left(y_{o c}-y_{o c^{\prime}}-\sum_{r^{\prime}=1}^{r-1} y_{o p_{r^{\prime} c^{\prime}}}\right) D_{o c^{\prime}}^{D} \forall 0 \in O, c \in C, c^{\prime} \in C, r \in\{1,2, \ldots,|C|-1\} \mid P r c^{\prime}=c$

$\sum_{c \in C} x_{o h c}^{D}=S_{o h}^{D}+S_{o h}^{A} \quad \forall 0 \in O, h \in H$

$\sum_{c \in C} x_{o h c}^{R}=S_{o h}^{D} \quad \forall o \in O, h \in H$

$x_{o h c}^{R} \leq S_{o h}^{D} y_{o c} \quad \forall 0 \in O, h \in H, c \in C$

$x_{o h c}^{D} \leq\left(S_{o h}^{D}+S_{o h}^{A}\right) y_{o c} \quad \forall 0 \in O, h \in H, c \in C$ $x_{o h c}^{E} \leq S_{o h}^{D} y_{o c} \quad \forall o \in O, h \in H, c \in C$

$d_{o c}^{A}=D_{o c}^{A} y_{o c}+\sum_{c^{\prime} \in C} d_{o c^{\prime} c}^{A} \forall 0 \in O, c \in C$

$d_{o c^{\prime} c}^{\mathrm{A}} \geq\left(y_{o c}-y_{o c^{\prime}}-\sum_{r^{\prime}=1}^{r-1} y_{o p_{r^{\prime} c^{\prime}}}\right) D_{o c^{\prime}}^{A} \quad \forall 0 \in O, c \in C, c^{\prime} \in C, r \in\{1,2, \ldots,|C|-1\} \mid P_{r c^{\prime}}=c$

$d_{o c}^{A}=\sum_{a \in A_{o c}} x_{o a c}^{A} \forall o \in O, c \in C$

$\sum_{c \in C \mid t_{m c}^{M} \leq T_{o}} y_{o c} \geq 1 \quad \forall o \in O, m \in M$

$z_{c} \in\{0,1\} \quad \forall c \in C$

$y_{o c} \in\{0,1\} \quad \forall o \in O, c \in C$

$x_{\text {ohc }}^{R} \geq 0 \quad x_{\text {ohc }}^{E} \geq 0 \quad x_{o h c}^{D} \geq 0 \quad \forall 0 \in O, h \in H, c \in C$

$x_{o a c}^{A} \geq 0 \quad \forall 0 \in O, a \in A, c \in C$

$d_{o c}^{A} \geq 0 \quad \forall 0 \in O, c \in C$

$d_{o c^{\prime} c}^{D} \geq 0 \quad d_{o c^{\prime} c}^{A} \geq 0 \quad \forall 0 \in O, c \in C, c^{\prime} \in C$

The objective function (1) minimizes the total weighted travel time. The first terms include the travel time from donor hospital to donor center $\left(t_{h c}^{T} x_{\text {ohc }}^{D}\right)$ (the transportation of blood samples) and back $\left(t_{h c}^{B} x_{\text {ohc }}^{D}\right)$ (the transplant co-ordinator and his transplant team travel to the donor hospital to remove the organ). During these time periods, the organ is still in the donor's body. Consequently, this time is not included in the cold ischemia time. Therefore, this travel time might be considered less critical than the travel time subject to the cold ischemia time, represented by the other terms in the objective function. For this reason, a weight, $w$ $(0 \leq w \leq 1)$, is added, which allows for setting the relative importance of that part of the total travel time not related to the cold ischemia time. The third term in the objective function contains the travel time from donor hospital to recipient center. The last term indicates the travel time between the airports and recipient centers for organs that come from abroad.

Constraint set (2) ensures that a center can only be open for a particular organ if the center itself is open.

Constraint (3) defines the budget restriction.

Constraint set (4) makes sure that the total demand for organs at the recipient centers coming from domestic donors equals the total flow out of the donor hospitals.

Constraint sets (5) and (6) calculate the organ flow from each donor hospital to each recipient center. This flow equals zero if the travel time between the donor hospital and the recipient center exceeds the cold ischemia time, as indicated in constraint set (5). If not, the travel time is calculated by constraint set (6). The flow consists of two terms: $\left(\frac{D_{o c}^{D} y_{o c}+\sum_{c^{\prime} \in C} d_{o c^{\prime} c}^{D}}{\sum_{c^{\prime} \in C^{\prime} D_{o c^{\prime}}}^{D}}\right) S_{o h}^{D}$ and $x_{o h c}^{E}$. We start from Fig. 7 to explain the first term. 


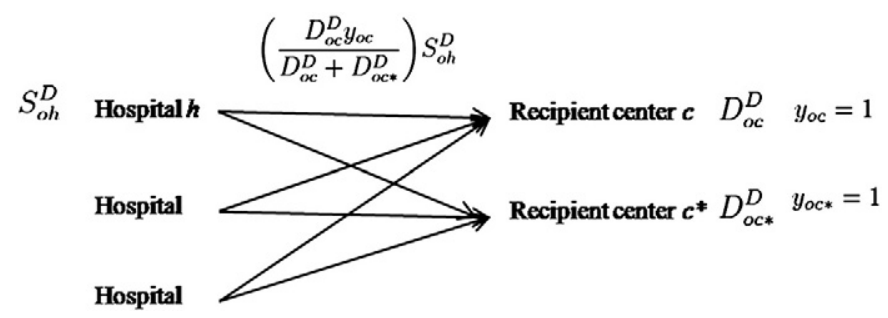

Fig. 7. The flows in case of no demand shift (all recipient centers are open) and no extra flow (all donor hospitals are situated within a travel time smaller than or equal to the cold ischemia time from each open recipient center).

In Fig. 7, it is assumed that all centers are open. Hence, there is no demand shift from closed centers to open centers $\left(\sum_{c^{\prime} \in C} d_{o c^{\prime} c}^{D}=0\right)$. Moreover, all donor hospitals are situated within a travel time not exceeding the cold ischemia time from each open center. Thus, all flows are allowed. In this scenario, the flow between donor hospital and recipient center equals a fraction of the donor hospital's supply $\left(=S_{o h}^{D}\right)$. This fraction equals the demand of the recipient center, divided by the total demand over all recipient centers, see expression $\left(\frac{D_{o c}^{D} y_{o c}}{D_{o c}^{D}+D_{o c *}^{D}}\right)$ in the example of Fig. 7. There cannot be flow of organ $o$ to a center $c$ if $y_{o c}=0$, which explains the presence of $y_{o c}$ in the numerator. Now, we move to the situation in which not all centers are open. In this case, demand will be shifted between recipient centers. The organ demand of a closed center is shifted to the nearest open center, as illustrated in Fig. 8.

The shifted demand from center $c^{\prime}$ to center $c$ is represented by the variable $d_{o c c^{\prime}}^{D}$. Constraint set (7), discussed hereafter, ensures the correct calculation of variable $d_{o c c^{\prime}}^{D}$. First, we continue the explanation of constraint set (6). To this aim, we introduce Fig. 9, which extends the situation described in Fig. 7.

Fig. 9 illustrates how shifted demand to a particular center is added in the numerator in the first term of the right hand side of constraint set (6). We now move to the explanation of the second term $\left(=x_{\text {ohc }}^{E}\right)$ in the right hand side of constraint set (6). To this aim, we introduce Fig. 10, which depicts the situation in which the travel time between a donor hospital and a recipient center is too large to allow for a timely, i.e., within the cold ischemia time, transplantation.

The variable $x_{o h c}^{E}$ can only take a positive value, when there is at least one open center situated too far (not within a travel time smaller than or equal to the the cold ischemia time) from donor hospital $h$. Note that, in order to minimize the objective function, the model will always assign this extra flow to the nearest (to donor hospital $h$ ) open recipient center. This is to conform to reality. In this case the recipient will travel to this nearest open transplant center. This final scenario completes the explanation of constraint set (6) and is represented in Fig. 11

Constraint set (7) calculates the shifted demand from each closed center $c^{\prime}$ to each open center $c$. Obviously, the demand from $c^{\prime}\left(=D_{o c^{\prime}}^{D}\right)$ can only be shifted from $c^{\prime}$ to $c$ if $c^{\prime}$ is closed and $c$ is open, a situation which is described by the first two terms, $y_{o c}-y_{o c^{\prime}}$, in the right hand side of the constraint set. Furthermore, since demand is only shifted to

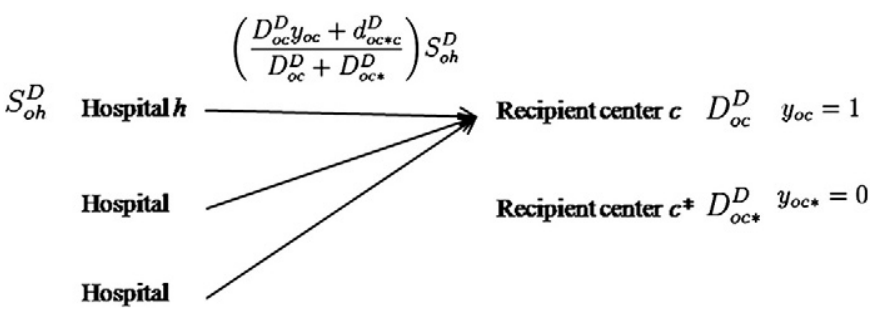

Fig. 9. The flows in case there is a demand shift (not all recipient centers are open) but no extra flow (all donor hospitals are situated within a travel time smaller than or equal to the cold ischemia time from each open recipient center). Observe that, in this particular case, the complete supply of each donor hospital goes to the single open center $c\left(a s d_{o c}^{D}=D_{o c}^{D}\right)$.

the nearest open center, the shifted demand can again be zero if there is any center open closer to center $c^{\prime}$ than center $c$, a factor which explains the last term, $-\sum_{r^{\prime}=1}^{r-1} y_{o p_{r^{\prime} c^{\prime}}}$.

Constraint set (8) ensures that the total flow out of a donor hospital to the donor centers equals the total organ supply (for domestic transplantations and transplantations abroad) at that donor hospital. Recall that each organ, whether it will be transplanted by a domestic center or a center abroad, generates a flow from the donor hospital to the donor center (blood samples) and back (transplant co-ordinator and transplant team).

Constraint set (9) ensures that all supply at each donor hospital is sent out to the recipient centers.

Constraint sets (10) and (11) guarantee that there is no flow to a closed center, that is, neither to a recipient center, see (10), nor to a donor center, see (11). In these constraints, both $S_{\text {oh }}^{D}$ and $\left(S_{o h}^{D}+S_{o h}^{A}\right)$ act as big $M$.

Constraint set (12) ensures that there can only exist an extra flow of an organ from a donor hospital to a recipient center, if this recipient center is open.

Constraint set (13) calculates, for each organ, the number of transplantations in a particular center from foreign donors. This number equals the center's international demand, increased by the shifted international demand of (nearby) closed centers. The latter is determined by constraint set (14), which is similar to the shifted domestic demand calculated in constraint set (7).

Constraint set (15) ensures that the international demand results in a flow from a chosen airport to the recipient center. Note that, in order to minimize the objective function, the model will always select the nearest airport. This corresponds to reality, as international organs enter the country through the airport nearest to the recipient center.

Constraint set (16) models the covering restriction: for each organ, at least one transplant center must be open within a particular travel time from each municipality in the country.

Finally, constraint sets (17) to (22) define the domains of the decision variables.

Problem (1)-(22) is NP-hard, which can be shown by reduction. Consider an instance of problem (1)-(22) which only considers the flows between donor hospitals and donor centers (all other objective

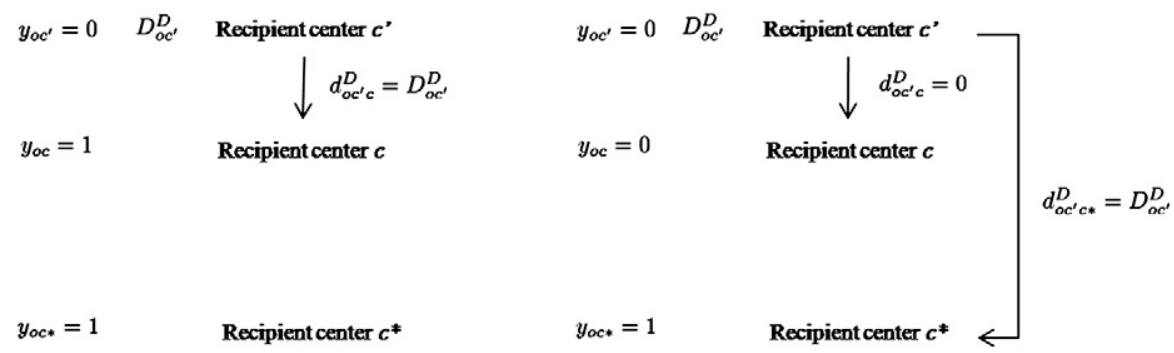

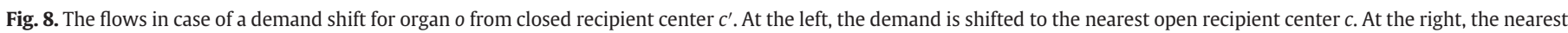
recipient center $c$ is not open for organ o $\left(y_{o c}=0\right)$, causing the demand of recipient center $c^{\prime}$ to be shifted to the second nearest open recipient center $c^{*}$. 


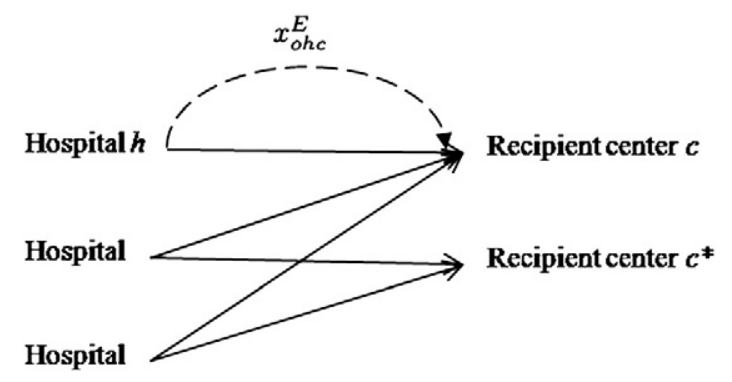

Fig. 10. Extra flow of organ $o$ from donor hospital $h$ to recipient center $c$. The absence of an arrow between donor hospital $h$ and center $c^{*}$ indicates that the required travel time is larger than the cold ischemia time. This causes an extra flow, $x_{o h c}^{E}$, from donor hospital $h$ to recipient center $c$, represented by the dashed line.

function coefficients equal 0). The covering restriction (16) is relaxed by assuming a very large right-hand side value. The budget constraint (3) is transformed into a restriction on the number of locations to be opened by considering an opening cost of 1 and a budget equal to the number of locations to be opened. Such an instance of problem (1)-(22) represents the $p$-median problem formulated by ReVelle and Swain [26] which is proven to be NP-hard by Kariv and Hakimi [16].

\section{Real-life application of the model}

\subsection{Data}

In this section, we will apply the model to the Belgian case. In explaining how the data were retrieved for Belgium, we follow the structure of the indices and sets, and the coefficients and right hand side constants in the order listed in Section 4.

We start with the indices and sets.

The potential transplant centers, and the organs they can handle are represented in Table 2. These centers are the eight approved transplant centers that currently have the requisite knowledge for transplant operations in Belgium.

Since we could not get an accurate picture of the donor network (i.e., the donor hospitals and the number of organs supplied), we defined from a list of all donor hospitals [5] every hospital with an operating room (OR) area as a potential donor hospital, resulting in a set of 150 donor hospitals (eight of which also serve as a transplant center). These donor hospitals can be found in Fig. 12.

The number of municipalities is determined by the number of postal codes in Belgium, which comes to 1135. There are five airports in Belgium.

All these data provide the following indices and sets when applied to Belgium:

$C=\{$ Aalst (OLVZ), Antwerp (UZA), Brussels (UZ VUB), Brussels (UCL St. Luc), Brussels (ULB Erasmus), Ghent (UZ Gent), Leuven (UZ Leuven), Luik (CHU Luik)\}

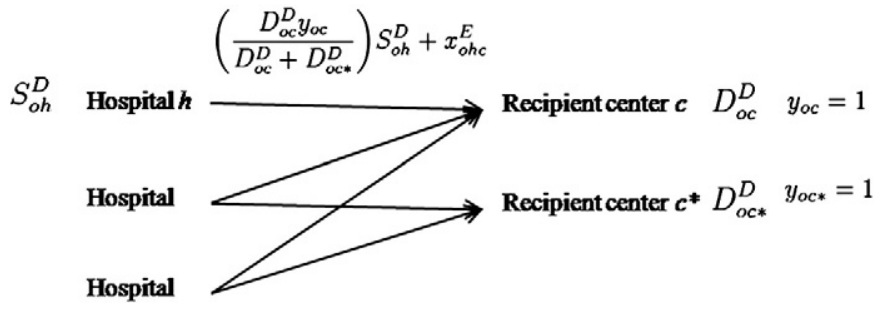

Fig. 11. The flows in case there is no demand shift (all recipient centers are open) but extra flow (not all donor hospitals are situated within a travel time smaller than or equal to the cold ischemia time from each open recipient center). The extra flow between donor hospital $h$ and recipient center $c$ is captured by the variable $. c, c^{\prime}, r, r^{\prime} \in C: x_{\text {ohc }}^{E}$. which equals the "canceled" flow between donor hospital $h$ and recipient center $c^{*}$.
Table 2

The Belgian transplant centers.

\begin{tabular}{llllll}
\hline Transplant center & $\begin{array}{l}\text { Heart } \\
(\mathrm{H})\end{array}$ & $\begin{array}{l}\text { Lung } \\
(\mathrm{Lu})\end{array}$ & $\begin{array}{l}\text { Pancreas } \\
(\mathrm{P})\end{array}$ & $\begin{array}{l}\text { Kidney } \\
(\mathrm{K})\end{array}$ & $\begin{array}{l}\text { Liver } \\
(\mathrm{Li})\end{array}$ \\
\hline Aalst-OLVZ (A1) & $\sqrt{ }$ & & & & \\
Antwerp-UZA (A2) & $\sqrt{ }$ & $\sqrt{ }$ & $\sqrt{ }$ & $\sqrt{ }$ & $\sqrt{ }$ \\
Brussels-UZ VUB (B1) & & & & $\sqrt{ }$ & \\
Brussels-UCL St. Luc (B2) & $\sqrt{ }$ & $\sqrt{ }$ & $\sqrt{ }$ & $\sqrt{ }$ & $\sqrt{ }$ \\
Brussels-ULB Erasmus (B3) & $\sqrt{ }$ & $\sqrt{ }$ & $\sqrt{ }$ & $\sqrt{ }$ & $\sqrt{ }$ \\
Ghent-UZ Gent (G) & $\sqrt{ }$ & $\sqrt{ }$ & $\sqrt{ }$ & $\sqrt{ }$ & $\sqrt{ }$ \\
Leuven-UZ Leuven (L1) & $\sqrt{ }$ & $\sqrt{ }$ & $\sqrt{ }$ & $\sqrt{ }$ & $\sqrt{ }$ \\
Luik-CHU Luik (L2) & $\sqrt{ }$ & $\sqrt{ }$ & $\sqrt{ }$ & $\sqrt{ }$ & $\sqrt{ }$ \\
\hline
\end{tabular}

$$
\begin{aligned}
& O=\{\text { heart, lung, pancreas, kidney, liver }\} \\
& |H|=150 \\
& |M|=1135 \\
& A=\{\text { Antwerp, Charleroi, Luik, Oostende, Brussels }\} .
\end{aligned}
$$

We now discuss the coefficients and right hand side constants.

To find the demand and supply for each organ, we analyzed the data obtained from $[2,3,9,11,28,30,32-35,37]$ for the years 2004 to 2009. From these data, we could retrieve the yearly demand for organ transplants at each recipient center supplied by domestic donors $\left(D_{o c}^{D}\right)$ as well as foreign donors $\left(D_{o c}^{A}\right)$. The organ supply in each donor hospital for domestic recipients $\left(S_{o h}^{D}\right)$ and for foreign recipients $\left(S_{o c}^{A}\right)$ can then be easily calculated as explained in Section 3 . The number of beds in each donor hospital is retrieved from (Belgische Federale Overheidsdiensten, 2010).

With respect to the costs of opening $(k)$ transplant centers and operating these centers for organ $o\left(k_{o}\right)$ and the budget $(B)$ for these costs, we assume imaginary costs (because these costs are not disclosed, and difficult to estimate). The maximal budget is assumed to equal the amount corresponding to opening all potential centers for the organs as represented in Table 2 .

In determining $t_{o}^{i s c h}$, we know that the following cold ischemia times are commonly used (N 2009): heart (240 min), lung (360 min), pancreas (600 min), kidney (1440 min) and liver (600 min).

For the following data parameters $\left(p_{r c}, t_{m c}^{M}, t_{h c}^{T}, t_{c h}^{B}\right.$, and $\left.t_{a c}^{A}\right)$, we need to estimate travel times. These times are realistic driving times retrieved from GoogleMaps [14].

In finding the maximal allowed travel time between any municipality and an open center for organ $o\left(T_{o}\right)$, we proceed as follows. We first allocate each municipality to the nearest transplant center in terms of travel time. Then, we denote the highest value among all these travel times as the value for $T_{o}$ (which equals $91.32 \mathrm{~min}$ ). We assume the same value of $T_{o}$ for all organs.

Finally, because Aalst (OLVZ; transplant center with index 1) is only authorized to perform heart (organ with index 1) transplants, and Brussels (UZ VUB; transplant center with index 3) kidney (organ with index 4) transplants, we add the following constraints for the Belgian case:

$y_{2,1}=y_{3,1}=y_{4,1}=y_{5,1}=0$

$y_{1,3}=y_{2,3}=y_{3,3}=y_{5,3}=0$

In this real-life application, we have 232 possible solutions (6 locations with 5 organs resulting in 30 binary decisions plus 2 locations with 1 organ). Hence, enumerating all possible combinations would be very time consuming. As shown in Section 5.3, the bounding mechanism provided by MILP dramatically reduces the required computation times. 


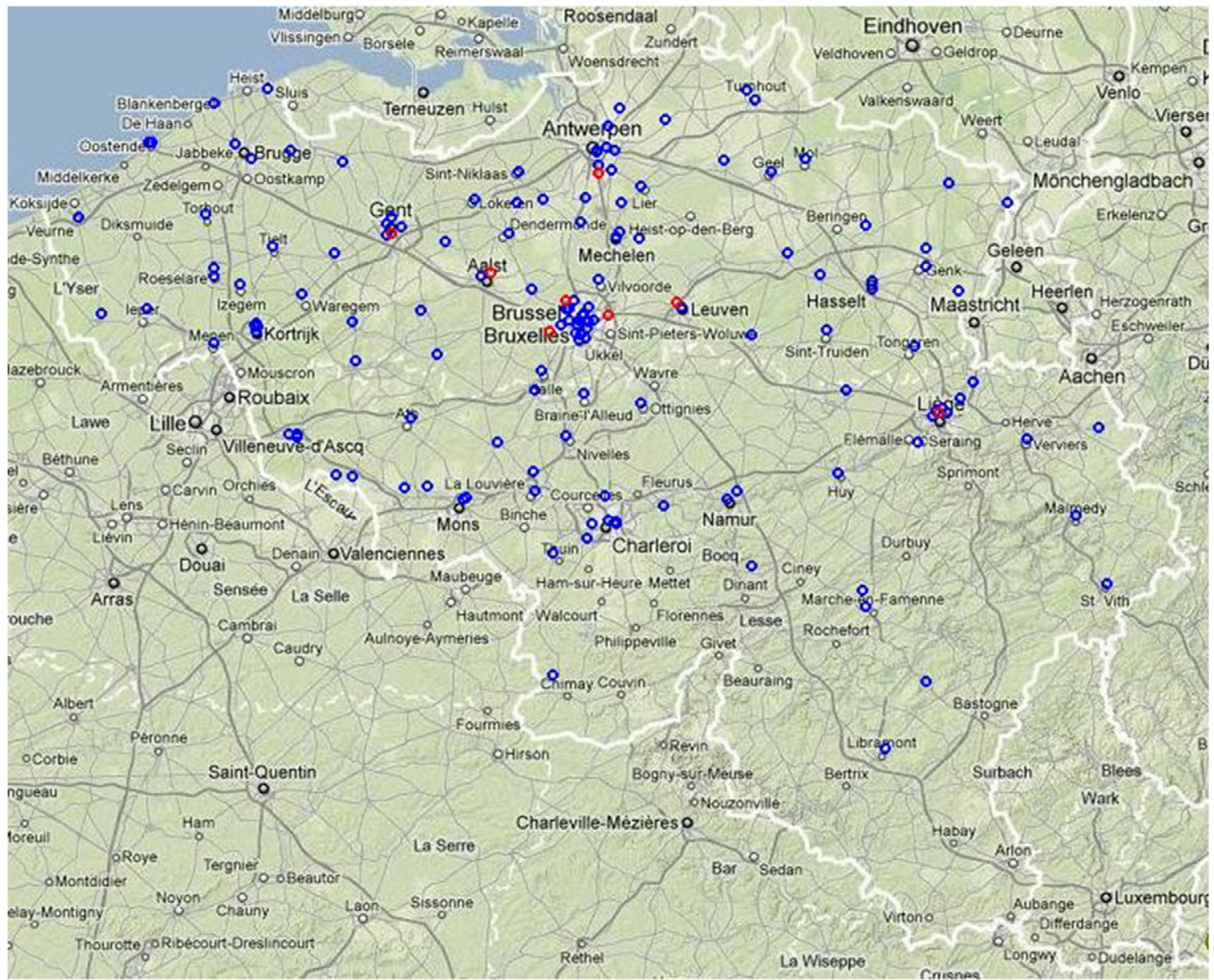

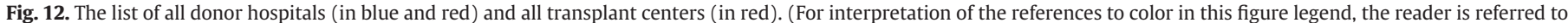
the web version of this article.)

\subsection{Sensitivity analysis}

In building the scenarios for the Belgian case, we will analyze the impact on the solution and computation time of changes in four elements.

The first element is the objective function. We look for the effect of setting $w$ equal to zero and to one in the objective function. Note that if $w$ equals zero, the objective function contains only the time components influencing the elapsed time between organ removal and implantation. In that case, we focus solely on the time components related to the cold ischemia time. When setting $w$ equal to one, we take into account all time components related to the total elapsed time between donor notification and organ arrival at a recipient center. In order to investigate the importance of the first time component (i.e., the component not influencing the time the organ is kept outside the body) in the final decision, we will include scenarios for a value of $w$ between zero and one.

The second element is the budget. We start with an unrestricted budget and investigate what happens if this budget is restricted to a specific percentage ( $75 \%$ and $50 \%$ ) of the total budget needed in the current Belgian situation (see Table 2).

The third element relates to the cold ischemia times. Given Belgium's limited surface, the maximal driving times between any two points in Belgium are below these cold ischemia times (the largest travel time between a donor hospital in Belgium and a transplant center is $142 \mathrm{~min}$ ). However, recall that for many other, larger countries cold ischemia times represent an important restriction. Decreasing the cold ischemia times in this study can then be seen as equivalent to modeling the facility location design of a larger country. Therefore, the cold ischemia times were incorporated in the model and their impact has been analyzed. Observe that in decreasing these cold ischemia times, not all transplant centers can function as a recipient center for all donor hospitals. In the remainder, we will represent the cold ischemia time (CIT) as follows: [CIT heart, CIT lung, CIT pancreas, CIT kidney, CIT liver].

The fourth element relates to the covering restriction. This restriction ensures that, for each organ, at least one transplant center is open within a particular travel time of each municipality in the country. Hence, when relaxing this constraint (by increasing this maximal allowed travel time), some centers might be closed. Note that we assume $w$ equal to zero in relaxing this constraint, because with $w$ equal to one, ceteris paribus, it is optimal to open all transplant centers (see Subsection 5.3).

The impact of changes in these four elements is analyzed using six instances, one for each of the years 2004 to 2009. The differences in these years consist of very small changes in yearly demand of the potential transplant centers. Analyzing these four elements results in 12 different scenarios, listed in Table 3, for each of the six years or, in total, 72 model runs.

\subsection{Results and discussion}

The experiments were done on a $3.00 \mathrm{Ghz}$ PC with $3.21 \mathrm{~Gb}$ of RAM using CPLEX® 12.1 (IBM ${ }^{\circledR}$ ) for solving the MILPs.

We first summarize the results for scenarios 1-12 in terms of the objective function (Fig. 13), the computation time and the extra flow (Fig. 14) for all years. The data corresponding to Figs. 13 and 
Table 3

The different scenarios for the Belgian case for 2004-2009.

\begin{tabular}{lllll}
\hline Scenario & $\begin{array}{l}\text { Objective } \\
\text { function }\end{array}$ & Budget & Cold ischemia times & $\begin{array}{l}\text { Covering } \\
\text { restriction }\end{array}$ \\
\hline 1 & $w=1$ & Not restricted & {$[240,360,600,1440,600]$} & 91.32 \\
2 & $w=0$ & Not restricted & {$[240,360,600,1440,600]$} & 91.32 \\
3 & $w=0.5$ & Not restricted & {$[240,360,600,1440,600]$} & 91.32 \\
4 & $w=0.1$ & Not restricted & {$[240,360,600,1440,600]$} & 91.32 \\
5 & $w=0.05$ & Not restricted & {$[240,360,600,1440,600]$} & 91.32 \\
6 & $w=0.01$ & Not restricted & {$[240,360,600,1440,600]$} & 91.32 \\
7 & $w=1$ & $75 \%$ & {$[240,360,600,1440,600]$} & 91.32 \\
8 & $w=1$ & $50 \%$ & {$[240,360,600,1440,600]$} & 91.32 \\
9 & $w=1$ & Not restricted & {$[100,130,150,200,150]$} & 91.32 \\
10 & $w=1$ & Not restricted & {$[90,90,90,90,90]$} & 91.32 \\
11 & $w=0$ & Not restricted & {$[240,360,600,1440,600]$} & 120 \\
12 & $w=0$ & Not restricted & {$[240,360,600,1440,600]$} & Not restricted \\
\hline
\end{tabular}

14 can be found in the appendix, in Tables A.1 and A.2, respectively. The open organ transplant centers are listed in Tables 4 and 5 (for 2009), and Table 6 (differences with 2009). For the definition of the symbols in Tables 4 and 5, we refer to Table 2.

When the objective function consists of only those travel times that are subject to the cold ischemia time $(w=0)$, a minimal number of centers is open (see scenarios 2,11 and 12 in Tables 4 and 5). This centralization can be explained as follows. Since each open center can function as a recipient center when an organ becomes available, it leads to an organ flow from each of the 150 donor hospitals to each of the open recipient centers. Hence, there will also be flow between donor hospitals and recipient centers that are situated at a large distance from each other. When a minimum of centrally situated center (s) are open, the total travel time between donor hospitals and the recipient center(s) will be minimized. When considering the whole objective function, the reverse applies: the optimal solution will open as many centers as possible. The reason is that the travel times between donor hospitals and donor centers are minimized when opening all centers, because each donor hospital will cooperate with the nearest open donor center.

When the weight of the travel times of the flow between donor hospitals and donor centers decreases (see scenarios 3, 4, 5, and 6 in Tables 4 and 5), less centers are open. When the weight is only $1 \%$ (see scenario 6 in Table 4) again a minimal number of centers is open. Summarizing, when the cold ischemia times are considered far more important than the total travel times, it is better to open less centers. This comes at the cost of a lower service level, as the recipients, and the transplant coordinators with their donor transplant teams will be confronted with longer travel times. Note that, independent of the weight factor, the objective function of the model is related to the 'sustainable value' of humanitarian concern. Indeed, minimizing the waiting time from the moment an organ becomes available till organ

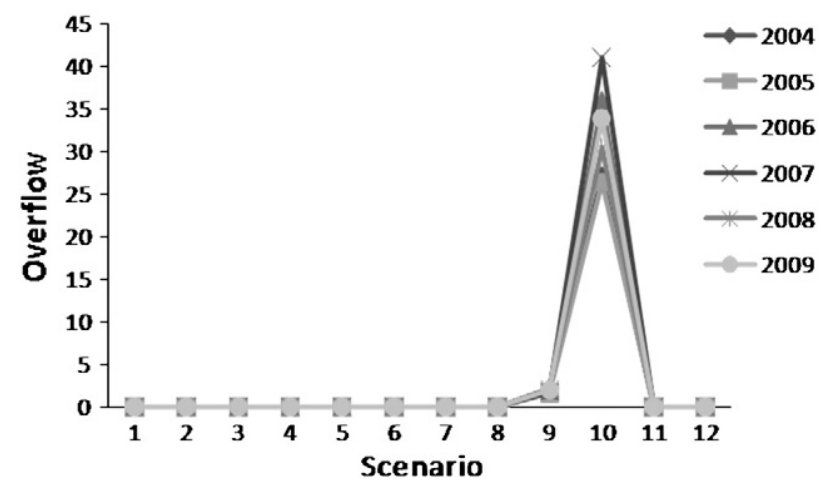

Fig. 14. The total extra flow for scenarios 1-12 for all years.

implantation (including a weight factor to reflect the criticality of the process after the organ's removal) increases to probability of the transplantation being successful.

A second reason for opening less centers might be a limited budget (see scenarios 7, and 8 in Tables 4 and 5).

When the cold ischemia times are reduced, some of the centers can no longer function as recipient centers for certain donor hospitals (see scenarios 9 and 10 in Tables 4 and 5). The shifted flow as a consequence of this restriction is represented by the extra flow (see scenarios 9 and 10 in Fig. 14) from these donor hospitals to other recipient centers. In reality, the recipient cannot have the transplantation in the nearest center open, but will be obliged to travel to a center that is situated within a travel time smaller than the cold ischemia time of the donor hospital. Obviously, the extra flow grows with smaller cold ischemia times (scenario 10 compared to scenario 9).

When the covering constraint is made less restrictive by increasing the maximal travel time between any municipality and its nearest transplant center, less centers (see scenarios 11, and 12 in Tables 4 and 5 ) are open compared to the original covering restriction (scenario 2 ). Thus, the original covering restriction is binding.

With respect to the computation times, the main conclusion is that, for the Belgian case, in all tested scenarios the model can be easily solved to optimality, with a maximal computation time of less than $8 \mathrm{~s}$. The model is most difficult to solve if there is a budget restriction (scenarios 7 and 8 ) or if the covering restriction is less (not) binding. The same analysis is valid for the other data instances (2004, 2005, 2006, 2007 and 2008).

Given the small yearly demand changes in the potential transplant centers, we observe from Table 6 that the basic scenarios (1 and 2) open the same transplant centers for each organ with only a few exceptions. Further we observe an identical shape of the curves representing the objective value for the different scenarios for all years

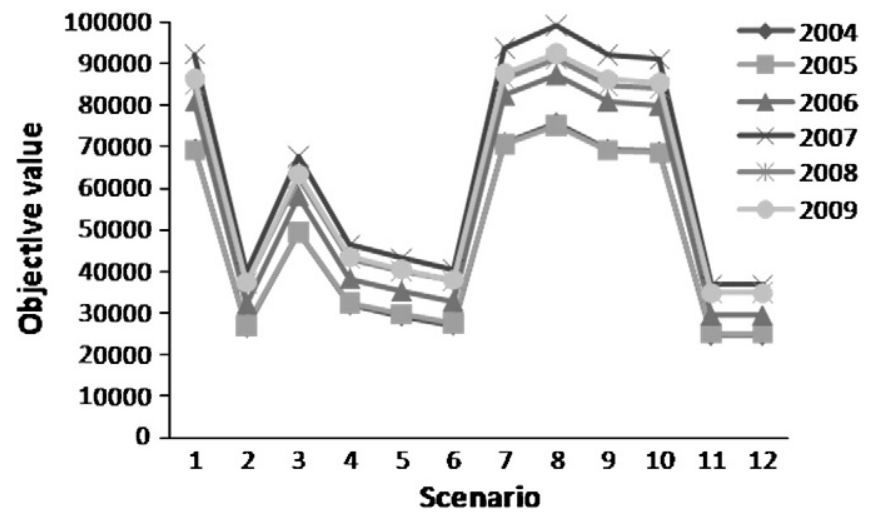

Table 4

The open organ transplant centers for scenarios 1-12 for 2009.

\begin{tabular}{|c|c|c|c|c|c|c|c|c|c|c|c|c|c|c|c|c|c|c|c|c|}
\hline \multirow[t]{2}{*}{2009} & \multicolumn{5}{|c|}{$\begin{array}{l}\text { Scenarios } \\
1,3,9,10\end{array}$} & \multicolumn{5}{|c|}{$\begin{array}{l}\text { Scenarios } \\
2,6\end{array}$} & \multicolumn{5}{|c|}{$\begin{array}{l}\text { Scenario } \\
4\end{array}$} & \multicolumn{5}{|c|}{$\begin{array}{l}\text { Scenario } \\
5\end{array}$} \\
\hline & $\mathrm{H}$ & $\mathrm{Lu}$ & $\mathrm{P}$ & K & $\mathrm{Li}$ & $\mathrm{H}$ & $\mathrm{Lu}$ & P & K & $\mathrm{Li}$ & $\mathrm{H}$ & $\mathrm{Lu}$ & $\mathrm{P}$ & K & $\mathrm{Li}$ & $\mathrm{H}$ & $\mathrm{Lu}$ & $\mathrm{P}$ & K & $\mathrm{Li}$ \\
\hline A1 & 1 & & & & & & & & & & & & & & & & & & & \\
\hline A2 & 1 & 1 & 1 & 1 & 1 & & & & & & & 1 & 1 & 1 & 1 & & 1 & & & 1 \\
\hline B1 & & & & 1 & & & & & 1 & & & & & 1 & & & & & 1 & \\
\hline B2 & 1 & 1 & 1 & 1 & 1 & & & 1 & & 1 & & & 1 & & 1 & & & 1 & & 1 \\
\hline B3 & 1 & 1 & 1 & 1 & 1 & 1 & 1 & 1 & 1 & 1 & 1 & 1 & 1 & 1 & 1 & 1 & 1 & 1 & 1 & 1 \\
\hline G & 1 & 1 & 1 & 1 & 1 & & 1 & & & & 1 & 1 & 1 & & & & 1 & 1 & & \\
\hline L1 & 1 & 1 & 1 & 1 & 1 & & & & & & & & & & & & & & & \\
\hline L2 & 1 & 1 & 1 & 1 & 1 & 1 & 1 & 1 & 1 & 1 & 1 & 1 & 1 & 1 & 1 & 1 & 1 & 1 & 1 & 1 \\
\hline
\end{tabular}

Fig. 13. The objective value for scenarios 1-12 for all years. 
Table 5

The open organ transplant centers for scenarios 1-12 for 2009 (continued)

\begin{tabular}{|c|c|c|c|c|c|c|c|c|c|c|c|c|c|c|c|c|c|c|c|c|}
\hline \multirow[t]{2}{*}{2009} & \multicolumn{5}{|c|}{ Scenario 7} & \multicolumn{5}{|c|}{ Scenario 8} & \multicolumn{5}{|c|}{ Scenario 11} & \multicolumn{5}{|c|}{ Scenario 12} \\
\hline & $\mathrm{H}$ & Lu & $\mathrm{P}$ & K & $\mathrm{Li}$ & $\mathrm{H}$ & Lu & $\mathrm{P}$ & K & $\mathrm{Li}$ & $\mathrm{H}$ & Lu & $\mathrm{P}$ & K & $\mathrm{Li}$ & $\mathrm{H}$ & Lu & $P$ & K & $\mathrm{Li}$ \\
\hline A1 & & & & & & & & & & & & & & & & & & & & \\
\hline A2 & 1 & 1 & & 1 & 1 & & & & 1 & 1 & & & & & & & & & & \\
\hline B1 & & & & & & & & & & & & & & 1 & & & & & 1 & \\
\hline B2 & & 1 & 1 & 1 & 1 & & & & & & 1 & & 1 & & 1 & & & 1 & & 1 \\
\hline B3 & 1 & 1 & & 1 & 1 & 1 & 1 & 1 & 1 & 1 & 1 & 1 & & & & 1 & 1 & & & \\
\hline G & 1 & 1 & 1 & 1 & 1 & 1 & 1 & & 1 & 1 & & & & & & & 1 & & & \\
\hline L1 & & & & 1 & 1 & & & & & & 1 & & 1 & 1 & 1 & & & & & \\
\hline L2 & 1 & 1 & 1 & 1 & 1 & 1 & 1 & 1 & 1 & 1 & & 1 & & & & & 1 & & & \\
\hline
\end{tabular}

(Fig. 13). In other words, the model proves to be robust when taking into account uncertain conditions in the form of small yearly demand changes in the potential transplant centers.

Finally, we relax the assumption of deterministic travel times. The travel times are estimated based on a regression model which measures the travel times from donor hospital to a transplant center as a function of the distance. This regression model also provides us with standard deviations on these estimates. We have used this information to study the effect of travel times uncertainty on the optimal outcome of the model. To this aim, we have run the model four times, each time based on a different sample of travel times. These travel times are drawn from normal distribution characterized by the obtained average and standard deviation from the regression model. As the demand data is relatively stable throughout the years, we limited this analysis to the year 2009. The results indicate that the optimal set of transplant centers to open in our initial solution, based on deterministic travel times, was very comparable to the sets found based on stochastic travel times. More precisely, in the stochastic settings, no less than $92 \%$ of the $0 / 1$ decisions whether or not to open a center for an organ had the same value as the value obtained in the deterministic setting. We observed, however, important differences across the organs and scenarios. With respect to the organs, the percentage of differences ranged from $6 \%$ (liver) to $11 \%$ (heart). We conclude that the results from the MILP model are most reliable for the liver, while the results for the heart are the least robust with respect to stochastic travel times. With respect to the scenarios, the percentage of differences ranged from $0 \%$ (scenario 6 ) to $19 \%$ (scenario 12). We conclude that, in case that there is no covering restriction nor a budget restriction, and the travel times before the organ removal are considered not important at all (scenario 12) the results of the deterministic model are the least robust. In this scenario, the solution of the deterministic model must be complemented by a sensitivity analysis on the travel times in order to be able to make justified transplant center opening or closing decisions.

\section{Conclusion and future research}

The organ transplant process is a typical example of a process buffered by time, instead of inventory and/or capacity. Indeed, the whole process, characterized by a variable demand and a variable supply,

Table 6

Difference with respect to open organ transplant centers compared to scenarios 1 and 2 of 2009 .

\begin{tabular}{ll}
\hline & Difference \\
\hline 2004 & Difference in scenario 2 for pancreas \\
2005 & Difference in scenario 2 for pancreas and liver \\
2006 & No difference \\
2007 & Difference in scenario 2 for liver \\
2008 & No difference \\
\hline
\end{tabular}

suffers from two constrains. The first one is the cold ischemia-time which is the maximal time the organ can be kept outside the body. This very short shelf life causes the organs not to be storable. The second one is the supply being determined by donor death which fixes the capacity needed to fulfill the demand for organs. As a result, the recipient requiring an organ will have to wait, which is clearly visible by the long waiting lists for organ transplants.

The model developed in this paper aims at minimizing that part of the waiting time from the moment an organ becomes available till organ implantation, by looking for the optimal set of transplant centers to open for each organ. On top, the different time components receive a weight, enabling to indicate the extent to which the time before the organ's removal from the donor body is considered less crucial as compared to the time after removal (i.e., related to the cold ischemia time).

The MILP model for optimizing the facility (i.e. transplant center) location design for organ transplants presented in the paper, can thus be viewed as a rapid model, partly taking into account the stochastic setting. The model reaches the desired operational performance in terms of costs (i.e., a limit on the installation and operating costs of the transplant centers) and responsiveness (minimizing the time between donor notification and organ implantation) within very small computation times. Note that the performance measure used in the objective function of the model might be related to the "sustainable value' of humanitarian concern. Minimizing the waiting time from the moment an organ becomes available till organ implantation, including a weight factor for the elapsed time before the organ's removal from the donor body in order to reflect the criticality of the process after the organ's removal, is crucial for a successful transplantation.

The MILP model has been applied to the Belgian case, involving different scenario analyses on real-life data from 2004-2009. The main conclusions can be summarized as follows. If, on the one hand, the objective is merely to minimize the time the organ is kept outside the body, only a few centers are opened resulting in centralization. If, on the other hand, the total time is minimized between the moment a donor 'arrives' and the organ transplant, then there is a trend towards decentralization with many open transplant centers. A smaller cold ischemia time leads to extra flows from certain donor hospitals to nearby transplant centers. A budget restriction forces some centers to be closed at the cost of a decreased service level. Fewer centers are also opened when the covering constraint is made less restrictive (by increasing the maximal travel time between any municipality and its nearest transplant center). Using stochastic travel times (assumed to be normally distributed with parameters derived from a regression analysis on the initial times) hardly changes the optimal solution. All MILP models for the Belgian case are easily solved involving very small computation times.

However, the model can be enhanced on a few points. In the current model, the demand from a closed center is shifted to the nearest open recipient center. This may deviate from reality as a transplant center covers demand from recipients who reside "around" the center. If, e.g., the transplant center UZ Leuven (Leuven) is closed, it might be more realistic to shift part of the demand to Antwerp (UZA), Brussels (UCL St. Luc), and Luik (CHU Luik). Another extension would be to introduce shipping agents in the model. The question here arises where to locate these shipping agents in order to minimize the total travel time as part of the elapsed time between donor organ arrival and implantation. A third extension consists of introducing recipients in the model. Until now, they are only indirectly part of the model through the covering restriction. Adding recipients' demand into the model would enable to take into account that recipients' travel times to recipient centers might increase the total time between donor notification and organ transplantation. This will be the case whenever the recipient's travel time to the recipient center exceeds the travel time from donor hospital to donor center to recipient center. In case the yearly supply at the donor hospitals is not stable over the years, we could think of introducing stochastic supply (i.e., a distribution function for each donor hospital) 
into the model and adding stochastic components in the objective function and/or stochastic constraints (e.g., travel times must be lower than $\mathrm{x}$ hours in $95 \%$ of the cases).

\section{Appendix A}

Table A.1

The objective value for scenarios 1-12 for all years.

\begin{tabular}{lllllll}
\hline Scenario & 2004 & 2005 & 2006 & 2007 & 2008 & 2009 \\
\hline 1 & 73139 & 72488 & 83294 & 89949 & 81601 & 82707 \\
2 & 30134 & 30312 & 34503 & 37559 & 33901 & 33845 \\
3 & 53023 & 52657 & 60530 & 65457 & 59287 & 59872 \\
4 & 35544 & 35645 & 40620 & 44158 & 39866 & 39961 \\
5 & 32896 & 33042 & 37606 & 40956 & 36948 & 36993 \\
6 & 30693 & 30873 & 35138 & 38254 & 34525 & 34483 \\
7 & 74640 & 73814 & 84629 & 91462 & 83060 & 84033 \\
8 & 79409 & 78451 & 89615 & 96832 & 87906 & 88901 \\
9 & 73070 & 72444 & 83222 & 89896 & 81556 & 82646 \\
10 & 72451 & 71838 & 82234 & 88724 & 80835 & 81761 \\
11 & 29373 & 29535 & 33275 & 36098 & 33186 & 32984 \\
12 & 28217 & 28449 & 31787 & 34494 & 31660 & 31321 \\
\hline
\end{tabular}

Table A.2

The total extra flow for scenarios 1-12 for all years.

\begin{tabular}{lcccccc}
\hline Scenario & 2004 & 2005 & 2006 & 2007 & 2008 & 2009 \\
\hline 1 & 0 & 0 & 0 & 0 & 0 & 0 \\
2 & 0 & 0 & 0 & 0 & 0 & 0 \\
3 & 0 & 0 & 0 & 0 & 0 & 0 \\
4 & 0 & 0 & 0 & 0 & 0 & 0 \\
5 & 0 & 0 & 0 & 0 & 0 & 0 \\
6 & 0 & 0 & 0 & 0 & 0 & 0 \\
7 & 0 & 0 & 0 & 0 & 0 & 0 \\
8 & 0 & 0 & 0 & 0 & 0 & 0 \\
9 & 2.18 & 1.55 & 2.06 & 1.76 & 1.97 & 1.97 \\
10 & 27.22 & 26.39 & 36.02 & 41.04 & 30.41 & 33.87 \\
11 & 0 & 0 & 0 & 0 & 0 & 0 \\
12 & 0 & 0 & 0 & 0 & 0 & 0
\end{tabular}

\section{References}

[1] O. Alagoz, A.J. Schaefer, M.S. Roberts, Optimizing organ allocation and acceptance in: P. Pardalos, E. Romeijn (Eds.), Handbook of Optimization in Medicine, Springer, 2009, pp. 1-24.

[2] B. Amerijckx, Transplant coordinator UZ VUB, personal communication, August $20,2009$.

[3] E. Angenon, Transplant coordinator ULB Erasmus, personal communication, December 11, 2009.

[4] N.R. Banner, H.L. Thomas, E. Curnow, J.C. Hussey, C.A. Rogers, R.S. Bonser, The importance of cold and warm cardiac ischemia for survival after heart transplantation, Transplantation 86 (2008) 542-547.

[5] Belgische Vereniging der Ziekenhuizen, Belgische federale overheidsdiensten, www.hospitals.be, http://www.belgium.be/nl/gezondheid/gezondheidszorg/ medische diensten/ziekenhuizen, accessed November 26, 2010.

[6] M.E. Bruni, D. Conforti, N. Sicilia, S. Trotta, A new organ transplantation locationallocation policy: a case study of Italy, Health Care Management Science 9 (2006) $125-142$.

[7] S. Chopra, P. Meindl, Supply Chain Management, Pearson, 2007.

[8] M.S. Daskin, L.K. Dean, Location of health care facilities, in: M.L. Brandeau, F. Sainfort W.P. Pierskalla (Eds.), Operations Research and Health Care, A Handbook of Methods and Applications, Kluwer's International Series, Dordrecht, 2004, pp. 43-76.

[9] B. Desschans, Transplant coordinator UZ Leuven, personal communication, August $20,2009$.

[10] E. Domínguez, J. Muñoza, A neural model for the p-median problem, Computers and Operations Research 35 (2008) 404-416.

[11] Eurotransplant, http://www.eurotransplant.orgaccessed November 26, 2010.

[12] H. Fallah, A.N. Sadigh, M. Aslanzadeh, Covering problem, in: R.Z. Farahani, M. Hekmatfar (Eds.), Facility Location: Concepts, Models, Algorithms and Case Studies, Springer, 2009, pp. 145-176.

[13] P. Ghandforoush, T.K. Sen, A DSS to manage platelet production supply chain for regional blood centers, Decision Support Systems 50 (2010) 32-42.

[14] Google, http://maps.google.be(Accessed November 26, 2010).
[15] M. Jamshidi, Median location problem, in: R.Z. Farahani, M. Hekmatfar (Eds.), Facility Location: Concepts, Models, Algorithms and Case Studies, Springer, 2009, pp. 177-191.

[16] O. Kariv, S.L. Hakimi, An algorithmic approach to network location problems, SIAM Journal on Applied Mathematics 37 (1979) 539-560.

[17] A.S. Klein, E.E. Messersmith, L.E. Ratner, R. Kochik, P.K. Baliga, A.O. Ojo, Organ donation and utilization in the United States, 1999-2008, American Journal of Transplantation 10 (2010) 973-986.

[18] N. Kong, A.J. Schaefer, B. Hunsaker, M.S. Roberts, Maximizing the efficiency of the U.S. liver allocation system through region design, Management Science 56 (2010) 2111-2122.

[19] V. Maniezzo, I. Mendes, M. Paruccini, Decision support for siting problems, Decision Support Systems 23 (1998) 273-284.

[20] N. Mladenovića, J. Brimberg, P. Hansenc, J.A. Moreno-Pérez, The p-median problem: a survey of metaheuristic approaches, European Journal of Operational Research 179 (2007) 927-939.

[21] A. Oztekin, F.M. Pajouh, D. Delen, L.K. Swim, An RFID network design methodology for asset tracking in healthcare, Decision Support Systems 49 (2010) 100-109.

[22] A. Oztekin, Z.J. Kong, D. Delen, Development of a structural equation modelingbased decision tree methodology for the analysis of lung transplantations, Decision Support Systems 51 (2011) 155-166.

[23] W.P. Pierskalla, D.J. Brailer, Applications of operations research in health care delivery, in: S.M. Pollock, M.H. Rothkopf, A. Barnett (Eds.), Handbooks in Operations Research and Management Science, Operations Research and the Public Sector, Vol. 6, 1994, pp. 469-505, (Chapter 13, North-Holland).

[24] A. Rais, A. Viana, Operations research in healthcare: a survey, International Transactions in Operational Research 18 (2011) 1-31.

[25] H.K. Rajagopalana, C. Saydamb, J. Xiaoc, A multiperiod set covering location model for dynamic redeployment of ambulances, Computers and Operations Research 35 (2008) 814-826.

[26] C.S. ReVelle, R. Swain, Central facilities location, Geographical Analysis 2 (1970) 30-42.

27] C.S. ReVelle, H.A. Eiselta, M.S. Daskin, A bibliography for some fundamental problem categories in discrete location science, European Journal of Operational Research 184 (2008) 817-848.

[28] I. Tieken, Eurotransplant, personal communication, November 26, 2009.

[29] C. Toregas, C. ReVelle, Optimal location under time or distance constraints, Papers in Regional Science 28 (1972) 133-144.

[30] R. Troisi, Director BTS, Personal communication, February 23, 2010.

[31] N.B. Uehlinger, F. Beyeler, J. Weiss, H.P. Marti, F.F. Immer, Organ transplantation in Switzerland: impact of the new transplant law on cold ischaemia time and organ transports, Swiss Medical Weekly 140 (2010) 222-227.

[32] A. Van der Plas, Eurotransplant, personal communication, November 26, 2009.

[33] M. Van der Vennet, Transplant coordinator UZ Gent, personal communication, August 28, 2009.

[34] D. Van Deynse, Transplant coordinator UCL St. Luc, personal communication, July 7, 2009.

[35] W. Van Donink (), Transplant coordinator UZA, personal communication, August 24, 2009.

[36] J. Vroemen, J. Van der Vliet, B. Cohen, G. Persijn, Q. Lansbergen, G. Kootstra, The influence of warm and cold ischemic time on the outcome of cadaveric renal transplantation, European Surgical Research 16 (1984) 175-181.

[37] M. Walravens, Transplant coordinator OLVZ, personal communication, August 13, 2009

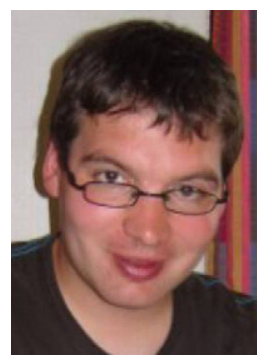

Jeroen Beliën holds a M.S. degree Commercial Engineering in Management Informatics (KU Leuven, 2001) as well as a PhD. in Applied Economics (KU Leuven, 2006). He is currently appointed associated professor at the Center for Modeling and Simulation at the Faculty of Economics and Management at HUBrussel (Belgium). He is also an affiliated professor at the Research Center for Operations Management of the Faculty of Business and Economics at KU Leuven (Belgium). He teaches courses in operations management and operations research. His research focuses on recent advances in optimization and simulation modeling with applications in health care problems (operating room scheduling, nurse scheduling, brachytherapy treatment planning, supply chain modeling of blood products and organ transplants, inventory management of medicines), business problems (workforce scheduling for aircraft line maintenance, vehicle routing for household waste collection) and sports (comparing league formats in Belgian football).

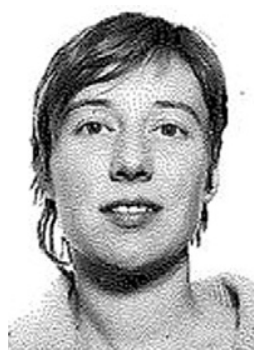

Liesje De Boeck is a researcher at the Center for Modeling and Simulation and associate professor at the Faculty of Business and Economics at HUBrussel (Belgium). She is also an affiliated professor at the Research Center for Operations Management of the Faculty of Business and Economics at KU Leuven (Belgium). She received her $\mathrm{PhD}$. in Applied Economics from the University of Antwerp (Belgium) in 2003 and obtained a M.S. degree Commercial Engineering from KU Leuven (Belgium) in 1997. She teaches courses in operations management and operations research. Her main research interests include discrete-event simulation, performance analysis, queueing approximations, planning and scheduling in production systems, and improving energy performance of buildings. 
12
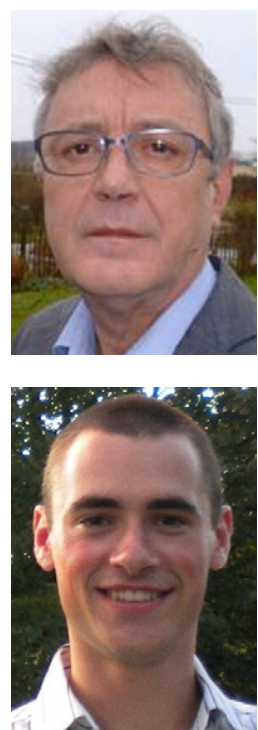

J. Beliën et al. / Decision Support Systems xxx (2012) xxx-xxx

Jan Colpaert is the chairman of the Center for Modeling and Simulation and a full professor at the HUBrussel (Belgium). He is also an affiliated professor at the Research Center for Operations Management of the Faculty of Business and Economics at KU Leuven (Belgium). He holds a M.S. degree in Mathematics from KU Leuven as well as a $\mathrm{PhD}$. in Sciences from KU Leuven. He teaches courses in mathematics, operations management and simulation. His main research interests are optimization and simulation modeling applied to health care problems and supply chain problems as well as cultural economics (pricing, price differentiation and product differentiation).

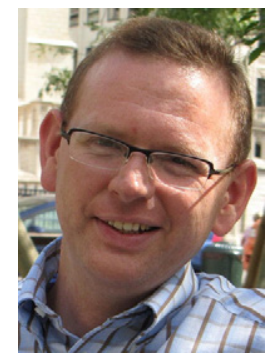

Filip Van den Bossche graduated in 1998 as a Commercial Engineer in Management Informatics and a qualified teacher in Economics and Applied Economics at KU Leuven (Belgium). At the same university, he obtained the degrees of M.S. in Applied Economics (1999) and Master in Statistics (2002). He received his PhD. in Applied Economics from Hasselt University (Belgium) in 2006. Filip is an associate professor at HUBrussel (Belgium) and affiliated professor at KU Leuven. He teaches courses in econometrics, statistics and advanced research methods. His research interests are in applied econometrics, sensitivity analysis and time series analysis.

Stijn Devesse is currently an auditor at KPMG. He holds a M.S. degree Commercial Engineering from HUBrussel (Belgium). 